\title{
Cationic Polymerization of Vinyl Compounds in the Presence of Tetra-n-butylammonium Salts. II. Polymerization Catalyzed by Iodine
}

\author{
Toshio Masuda, Yoshiro Miki, and Toshinobu Higashimura \\ Department of Polymer Chemistry, Kyoto \\ University, Kyoto, Japan. \\ (Received January 31, 1972)
}

\begin{abstract}
The cationic polymerization of 2-chloroethyl vinyl ether and $p$-methoxystyrene was studied in the presence of tetra- $n$-butylammonium salts such as $n-\mathrm{Bu}_{4} \mathrm{NClO}_{4}$, $n-\mathrm{Bu}_{4} \mathrm{NBF}_{4}$, and $n-\mathrm{Bu}_{4} \mathrm{NI}$. The polymerization was carried out using iodine as a catalyst at $0^{\circ} \mathrm{C}$ in methylene chloride, benzene-methylene chloride mixture, and nitrobenzene. The presence of $n-\mathrm{Bu}_{4} \mathrm{NClO}_{4}$ and $n-\mathrm{Bu}_{4} \mathrm{NBF}_{4}$ brought about an acceleration in reaction rates and an increase in the molecular weight of the polymers. A notable example was that the polymerization rate in the presence of $n-\mathrm{Bu}_{4} \mathrm{NClO}_{4}$ was $3 \times 10^{4}$ times faster than in the absence of the salt. The results of the experiment were explained by the presence of more than one counter-ion in the polymerization systems.

KEY WORDS Cationic Polymerization / 2-Chloroethyl Vinyl Ether / $p$-Methoxystyrene / Tetra- $n$-butylammonium Salt / Rate Acceleration / Counter-ion /
\end{abstract}

There have recently been several attempts to elucidate the mechanism of ionic polymerization by changing a counter-ion itself or the state of a counter-ion during polymerization. These are classified into two types of investigation. In one of them additives which can solvate a counter-ion are employed. In this connection, there are papers by Panayatov and his colleagues $^{1,2}$ in the field of cationic polymerization, and by Szwarc $^{3}$ and Tomoi $^{4}$ in anionic polymerization. The other investigation involves a study of the influence of added salts in the field of kinetics in cationic polymerization. ${ }^{5-9}$ Schulz $^{10}$ reports on the common-salt effect and $\mathrm{Hsieh}^{11}$ on the uncommon-salt effect in anionic polymerization.

The authors have found that added salts affect both polymerization rate and the molecular weight of the polymer in the cationic polymerization of styrene. The phenomena were attributed to the exchange of a counter-ion and the chaintransfer reaction. ${ }^{9}$

In this work the salt effect was studied in the cationic polymerization of a vinyl ether and a styrene derivative using iodine as a catalyst. There are two reasons why iodine is used as a catalyst: (a) the possibility that an added salt may work as a cocatalyst is avoided, for iodine does not need a cocatalyst, and (b) as iodine is a relatively weak catalyst, an inerease in the polymerization rate by adding a certain salt would be expected.

\section{EXPERIMENTAL}

\section{Materials}

The synthesis and purification of the salts used; tetra- $n$-butylammonium perchlorate ( $n$ $\mathrm{Bu}_{4} \mathrm{NClO}_{4}$ ), tetra- $n$-butylammonium fluoroborate $\left(n-\mathrm{Bu}_{4} \mathrm{NBF}_{4}\right)$, and tetra- $n$-butylammonium iodide $\left(n-\mathrm{Bu}_{4} \mathrm{NI}\right)$ are described elsewhere. ${ }^{9}$ 2-Chloroethyl vinyl ether (CEVE), $p$-methoxystyrene ( $p$ MOS $)^{12}$ and the solvents; methylene chloride, benzene, and nitrobenzene were purified in the usual manner. Iodine (E. Merck, resublimed reagent) was used without further purification.

\section{Procedures}

Details of the procedures are similar to those described previously. ${ }^{9}$ Polymerization was carried out at $0^{\circ} \mathrm{C}$ using iodine with $1.0 \mathrm{mmol} / l$ concentration mainly in methylene dichloride. Acetyl perchlorate $\left(\mathrm{AcClO}_{4}\right)$ and acetyl fluo- 
roborate $\left(\mathrm{AcBF}_{4}\right)$ were applied as catalysts for comparison with iodine. The polymerization rate was determined by measuring the monomer consumption by gas chromatography. The poly(2-chloroethyl vinyl ether) (poly(CEVE)) obtained was precipitated in a large amount of methanol-water mixture (volume ratio, $3: 1$ ). $\operatorname{Poly}(p$-methoxystyrene) (poly $(p$-MOS)) was precipitated in methanol. Viscosity number, $\eta_{\mathrm{sp}} / c$, of the polymers was measured in benzene at $30^{\circ} \mathrm{C}$.

\section{RESULTS}

The Effect of the Salts on Polymerization Rate

Iodine is a comparatively weak catalyst for cationic polymerization, with which CEVE and $p$-MOS polymerize at $0^{\circ} \mathrm{C}$ at a slow rate as shown in Figure 1. No induction period is

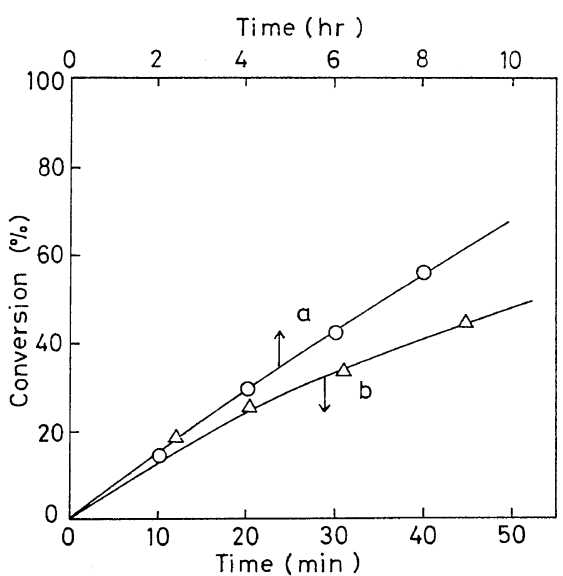

Figure 1. Time-conversion curves in the polymerization of CEVE and $p$-MOS catalyzed by iodine in methylene chloride at $0^{\circ} \mathrm{C}:[\mathrm{M}]_{0}, 0.50$ $\mathrm{mol} / l ;[\mathrm{C}]_{0}, 1.0 \mathrm{mmol} / l$; a $(\bigcirc), \mathrm{CEVE} ; \mathrm{b}(\triangle), p-$ MOS.

observed in the polymerizations. The polymerization rate was calculated at $40-50 \%$ conversion assuming monomer concentration to have a first-order effect; the polymerization rate of CEVE was $0.17 \% / \mathrm{min}$ and that of $p$-MOS $1.4 \% / \mathrm{min}$.

In the presence of $10 \mathrm{mmol} / l$ of $n-\mathrm{Bu}_{4} \mathrm{NClO}_{4}$, $n-\mathrm{Bu}_{4} \mathrm{NBF}_{4}$ or $n-\mathrm{Bu}_{4} \mathrm{NI}$ instead of iodine in the polymerization system, neither monomer was consumed after $10 \mathrm{hr}$. This confirms that the salts are not capable of initiating polymerization.

The authors concluded in the previous paper ${ }^{9}$ that the presence of a salt gives rise to the exchange of a counter-ion. Then, polymerization may proceed taking $\mathrm{ClO}_{4}{ }^{-}$and $\mathrm{BF}_{4}{ }^{-}$as a counter-ion when $n$ - $\mathrm{Bu}_{4} \mathrm{NClO}_{4}$ and $n-\mathrm{Bu}_{4} \mathrm{NBF}_{4}$ are added, respectively. Therefore, the polymerization rate was investigated applying $\mathrm{AcClO}_{4}$ and $\mathrm{AcBF}_{4}$ as catalysts in advance. These will produce the same counter-ions as the anions of the salts. $\mathrm{AcClO}_{4}$ polymerized both monomers instantaneously after a short induction period at a concentration as low as $0.010 \mathrm{mmol} / l$ (see Figure 2). When $0.10 \mathrm{mmol} / l \mathrm{AcBF}_{4}$ was used

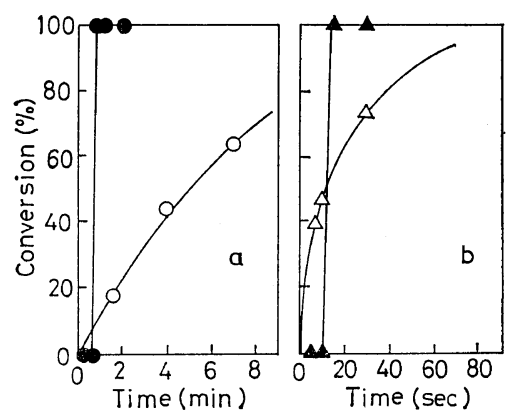

Figure 2. Time-conversion curves in the polymerization of CEVE and $p$-MOS catalyzed by $\mathrm{AcClO}_{4}$ and $\mathrm{AcBF}_{4}$ in methylene chloride at $0^{\circ} \mathrm{C}$ : $[\mathrm{M}]_{0}, \quad 0.50 \mathrm{~mol} / l$; (a) CEVE; (b) $p$-MOS; $\left[\mathrm{AcClO}_{4}\right]_{0}, 0.010 \mathrm{mmol} / l ; \bigcirc,\left[\mathrm{AcBF}_{4}\right]_{0}, 0.010 \mathrm{mmol} /$ $l ; \Delta,\left[\mathrm{AcClO}_{4}\right]_{0}, 0.010 \mathrm{mmol} / l ; \triangle,\left[\mathrm{AcBF}_{4}\right]_{0}, 0.10$ $\mathrm{mmol} / l$.

polymerization proceeded at a rate of $14 \% / \mathrm{min}$ for CEVE and $250 \% / \mathrm{min}$ for $p$-MOS. Accordingly, the order of catalytic activity lies as follows: $\mathrm{AcClO}_{4} \gg \mathrm{AcBF}_{4} \gg \mathrm{I}_{2}$.

The effect of $n-\mathrm{Bu}_{4} \mathrm{NClO}_{4}$ on the polymerization rate of the iodine system is shown in Figure 3. The presence of $n-\mathrm{Bu}_{4} \mathrm{NClO}_{4}$ leads to a remarkable increase in the reaction rate; the ratio of the rates $R_{\mathrm{p}} / R_{\mathrm{p}, 0}$ when $10.0 \mathrm{mmol} / l$ of $n-\mathrm{Bu}_{4} \mathrm{NClO}_{4}$ is present and absent, is about 600 for CEVE and about 120 for $p$-MOS. The acceleration is observed also in the presence of $n-\mathrm{Bu}_{4} \mathrm{NBF}_{4}$, but the extent is small compared with the acceleration by $n-\mathrm{Bu}_{4} \mathrm{NClO}_{4}$ (see Figure 4). The acceleration ratio, $R_{\mathrm{p}} / R_{\mathrm{p}, 0}$, when 10 


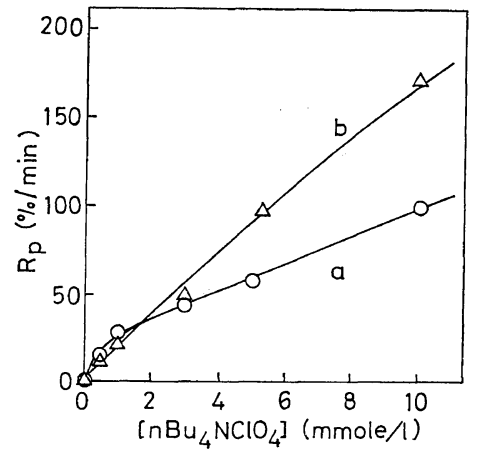

Figure 3. The effect of $n-\mathrm{Bu}_{4} \mathrm{NClO}_{4}$ on the polymerization rate of CEVE and $p$-MOS catalyzed by iodine in methylene chloride at $0^{\circ} \mathrm{C}:[\mathrm{M}]_{0}, 0.50$ $\mathrm{mol} / l$; a $(\bigcirc)$, CEVE, $R_{\mathrm{p}, 0}=0.17 \% / \mathrm{min} ; \mathrm{b}(\triangle), p$ MOS, $R_{\mathrm{p}, 0}=1.4 \% / \mathrm{min}$.

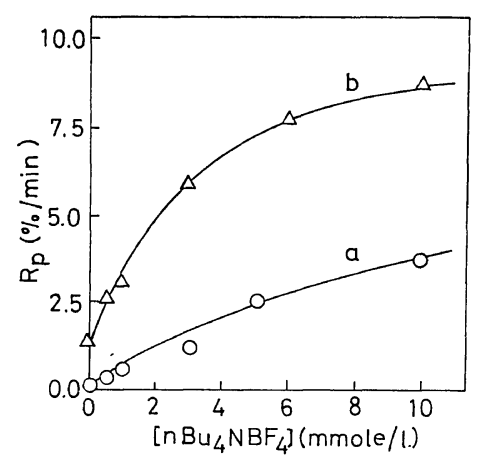

Figure 4. The effect of $n-\mathrm{Bu}_{4} \mathrm{NBF}_{4}$ on the polymerization rate of CEVE and $p$-MOS catalyzed by iodine in methylene chloride at $0^{\circ} \mathrm{C}:[\mathrm{M}]_{0}, 0.50$ $\mathrm{mol} / l:[\mathrm{C}]_{0}, 1.0 \mathrm{mmol} / l ;$ a $(\bigcirc), \mathrm{CEVE} ; \mathrm{b}(\triangle), p$ MOS.

$\mathrm{mmol} / l$ of $n-\mathrm{Bu}_{4} \mathrm{NBF}_{4}$ is present and absent is about 23 for CEVE and about 6.3 for $p$-MOS. Inversely, $n-\mathrm{Bu}_{4} \mathrm{NI}$ exhibits a conspicuous inhibition effect. Figure 5 shows that the polymerization of either monomer is almost completely inhibited with only $1.0 \mathrm{mmol} / l$ of the salt.

The effect of $n-\mathrm{Bu}_{4} \mathrm{NClO}_{4}$ was examined in the polymerization of CEVE in nitrobenzene and a mixture of benzene and methylene chloride (volume ratio, $3.0: 1.0$ ) as solvents. The result is shown in Figure 6. Polymerization rate depends very little on the concentration of $n-\mathrm{Bu}_{4} \mathrm{NClO}_{4}$ in nitrobenzene. In the case of a

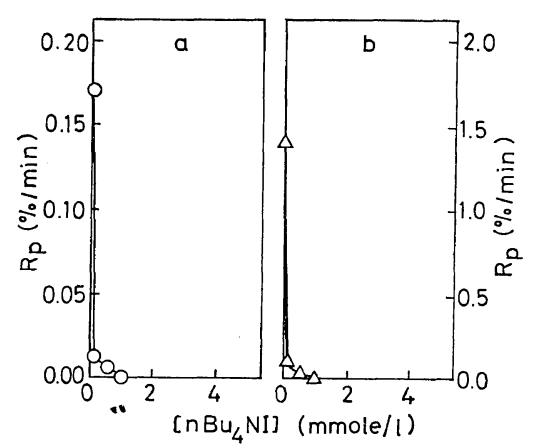

Figure 5. The effect of $n-\mathrm{Bu}_{4} \mathrm{NI}$ on the polymerization rate of CEVE and $p$-MOS catalyzed by iodine in methylene chloride at $0^{\circ} \mathrm{C}:[\mathrm{M}]_{0}, 0.50$ $\mathrm{mol} / l ;[\mathrm{C}]_{0}, 1.0 \mathrm{mmol} / l ;$ a $(\bigcirc), \mathrm{CEVE} ; \mathrm{b}(\triangle) p$ MOS.

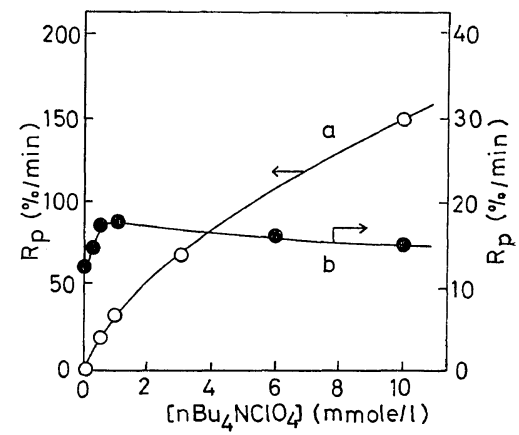

Figure 6. The effect of $n-\mathrm{Bu}_{4} \mathrm{NClO}_{4}$ on the polymerization rate of CEVE catalyzed by iodine at $0^{\circ} \mathrm{C}:[\mathrm{M}]_{0}, 0.50 \mathrm{~mol} / l ;[\mathrm{C}]_{0}, 1.0 \mathrm{mmol} / l ;$ a $(\mathrm{O})$, benzene-methylene chloride (volume ratio $3: 1$ ), $R_{\mathrm{p}, 0}=4.9 \times 10^{-3} \% / \mathrm{min} ; \mathrm{b}(\bullet)$, nitrobenzene $R_{\mathrm{p}, 0}=$ $12 \% /$ min.

mixture of benzene and methylene chloride the dependence is rather greater than in methylene chloride. In the former solvent, $R_{\mathrm{p}} / \boldsymbol{R}_{\mathrm{p}, 0}$ at $[n$ $\left.\mathrm{Bu}_{4} \mathrm{NClO}_{4}\right]=10 \mathrm{mmol} / \mathrm{l}$ is about 1.2 , and in the latter about $3 \times 10^{4}$. These values are in a sharp contrast.

The Effect of the Salts on the Molecular Weight of the Polymers

$90 \%$ by weight of the poly(CEVE) obtained is insoluble in a mixture of methanol and water (volume ratio, $3: 1$ ), and the viscosity number of the insoluble fraction was measured (see Table I). The viscosity of poly(CEVE) obtained with the three catalysts is in the sequence $I_{2}<$ 
Table I. Viscosity numbers of resultant polymers in methylene chloride at $0^{\circ} \mathrm{C}:[\mathrm{M}]_{0}, 0.50 \mathrm{~mol} / l$.

\begin{tabular}{cccc}
\hline Polymer & Catalyst & $\begin{array}{c}\text { Conversion, } \\
\%\end{array}$ & $\begin{array}{c}\eta_{\mathrm{sp}} / c,{ }^{\mathrm{a}} \\
\mathrm{d} l / \mathrm{g}\end{array}$ \\
\hline & $\mathrm{I}_{2}$ & 25.5 & 0.068 \\
Poly(CEVE) & & 50.6 & 0.072 \\
& $\mathrm{AcClO}_{4}$ & 100 & 0.189 \\
& $\mathrm{AcBF}_{4}$ & 44.1 & 0.211 \\
& & 79.3 & 0.237 \\
& & 18.3 & 0.182 \\
& $\mathrm{I}_{2}$ & 44.3 & 0.218 \\
& & 100 & 1.08 \\
& & 39.3 & 3.98 \\
& $\mathrm{AcClO}_{4}$ & 73.4 & 4.71 \\
\hline & $\mathrm{AcBF}_{4}$ & &
\end{tabular}

a Measurement conditions: benzene, $30^{\circ} \mathrm{C}$; concn of poly(CEVE), $1.00 \mathrm{~g} / \mathrm{d} l$; concn of poly( $p$-MOS), $2.00 \mathrm{~g} / \mathrm{d} l$.

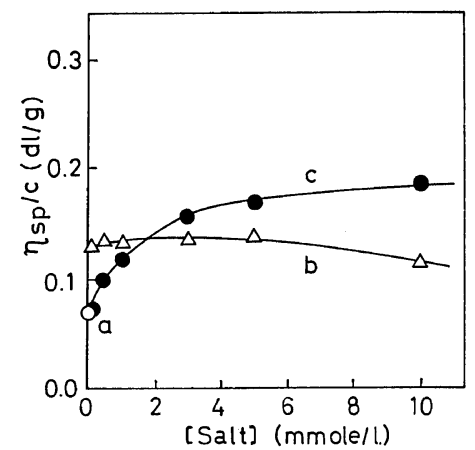

Figure 7. The effect of the salts on the molecular weight of poly(CEVE) obtained in methylene chloride at $0^{\circ} \mathrm{C}:[\mathrm{M}]_{0}, 0.50 \mathrm{~mol} / l$; and $[\mathrm{C}]_{0}, 1.0$ $\mathrm{mmol} / l$ (measurement of $\eta_{\mathrm{sp}} / c$ : temp, $30^{\circ} \mathrm{C}$; benzene, $1.00 \mathrm{~g} / \mathrm{d} l) ; \mathrm{a}(\bigcirc)$, no salt; b $(\triangle), n-\mathrm{Bu}_{4} \mathrm{NClO}_{4} ; \mathrm{c}$ (O), $n-\mathrm{Bu}_{4} \mathrm{NBF}_{4}$.

$\mathrm{AcClO}_{4}<\mathrm{AcBF}_{4}$. As seen from Figure 7, when $n-\mathrm{Bu}_{4} \mathrm{NClO}_{4}$ is present in the system with the iodine catalyst, the viscosity number is about 0.13 and constant, independent of the salt concentration. Meanwhile, with increasing addition of $n-\mathrm{Bu}_{4} \mathrm{NBF}_{4}$, the viscosity number increased gradually and reached about 0.019 . The sequence of viscosity increase, that is, no added salt $<n-\mathrm{Bu}_{4} \mathrm{NClO}_{4}<n-\mathrm{Bu}_{4} \mathrm{NBF}_{4}$ corresponds well with the sequence, $\mathrm{I}_{2}<\mathrm{AcClO}_{4}<\mathrm{AcBF}_{4}$.

The poly $(p$-MOS) obtained is precipitated quanatitatively in methanol. The dependence

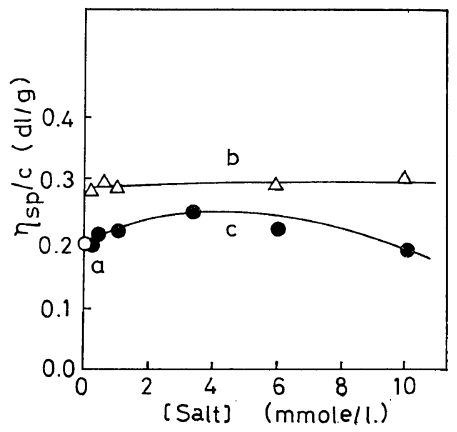

Figure 8. The effect of the salts of the molecular weight of poly( $p$-MOS) obtained in methylene chloride at $0^{\circ} \mathrm{C}: \quad[\mathrm{M}]_{0}, \quad 0.50 \mathrm{~mol} / l ; \quad[\mathrm{C}]_{0}, \quad 1.0$ $\mathrm{mmol} / l$ (measurement of $\eta_{\mathrm{sp}} / c$ : temp, $30^{\circ} \mathrm{C}$; benzene, $2.00 \mathrm{~g} / \mathrm{d} l) ; \mathrm{a}(\bigcirc)$, no salt; b $(\triangle), n-\mathrm{Bu}_{4} \mathrm{NClO}_{4} ; \mathrm{c}(\bullet)$, $n-\mathrm{Bu}_{4} \mathrm{NBF}_{4}$.

of the viscosity on the kind of catalyst is the same as that of poly(CEVE) (see Table I). The effect of the salts is shown in Figure 8 . The addition of $n-\mathrm{Bu}_{4} \mathrm{NClO}_{4}$ to the iodine-catalyzed system gives rise to an increase in the viscosity number (from 0.20 to 0.29 ) regardless of the amount of salt. In the case of $n-\mathrm{Bu}_{4} \mathrm{NBF}_{4}$, however, the viscosity numbers did not increase significantly, and when an excessive amout of $n-\mathrm{Bu}_{4} \mathrm{NBF}_{4}$ was present the viscosity number decreased. This could be explained by the action of the salt as a chain-transfer agent, as is also seen in the previous paper.

\section{DISCUSSION}

The above-mentioned results are summarized in Table II. These results have made clear that salts such as $n-\mathrm{Bu}_{4} \mathrm{NClO}_{4}, n-\mathrm{Bu}_{4} \mathrm{NBF}_{4}$, and $n$ $\mathrm{Bu}_{4} \mathrm{NI}$ greatly influence not only the reaction

Table II. Summary of changes in polymerization rate and molecular weight with the addition of the salts ${ }^{a}$

\begin{tabular}{|c|c|c|c|c|}
\hline & & $n-\mathrm{Bu}_{4} \mathrm{NClO}_{4}$ & $n-\mathrm{Bu}_{4} \mathrm{NBF}_{4}$ & $n-\mathrm{Bu}_{4} \mathrm{NI}$ \\
\hline \multirow{2}{*}{ CEVE } & $R_{\mathrm{p}}$ & $\Uparrow$ & $\uparrow$ & $\downarrow$ \\
\hline & $M W$ & "I & & \\
\hline \multirow{2}{*}{$p$-MOS } & $R_{\mathrm{p}}$ & $\Uparrow$ & $\uparrow$ & $\downarrow$ \\
\hline & $M W$ & II & & - \\
\hline
\end{tabular}

a. Catalyst, $\mathrm{I}_{2}$; solvent, $\mathrm{CH}_{2} \mathrm{Cl}_{2}$. 
rate but also the molecular weight of the polymers obtained in the cationic polymerization catalyzed by iodine.

Among the three catalysts, $\mathrm{AcClO}_{4}, \mathrm{AcBF}_{4}$, and iodine, order of the polymerization rate of CEVE and $p$-MOS is $\mathrm{AcClO}_{4} \gg \mathrm{AcBF}_{4} \gg \mathrm{I}_{2}$ and that of molecular weight $\mathrm{AcBF}_{4}>\mathrm{AcClO}_{4}>\mathrm{I}_{2}$. The presence and absence of the salts, $n$ $\mathrm{Bu}_{4} \mathrm{NClO}_{4}$ and $n-\mathrm{Bu}_{4} \mathrm{NBF}_{4}$ produces the same sequences for both polymerization rate and molecular weight with few exceptions. This is a strong indication that a counter-ion is able to exchange with the anion of an added salt during polymerization. It can be said that iodine has proved to be a good catalyst to test the exchange of a counter-ion since the acceleration is clearly observed when a salt having a stable anion is used.

A trace of $n-\mathrm{Bu}_{4} \mathrm{NI}$ retarded significantly the iodine-catalyzed polymerization, which might mean that the counter-ion is a polyiodide ion, $\mathrm{I}_{n}^{-}$and not monoiodide ion, $\mathrm{I}^{-}$. Monoiodide ion will be too unstable to serve as a counterion in cationic polymerization in the usual solvents.

The acceleration effect in polymerization rate of $p$-MOS is greater than that of CEVE. This means that the polymerization rate of $p$-MOS is more sensitive to the kind of counter-ion involved. The fact that the acceleration effect is greater in a less polar solvent means that a counter-ion exists nearer to the propagating end and polymerization rate depends more on the kind of counter-ion in a less polar solvent. Especially in nitrobenzene, a counter-ion seems to exist at so distant a position as to hardly affect the polymerization rate, owing to the solvation power as well as ionization power of the solvent. This reasoning is supported by the fact that the copolymer composition in the cationic copolymerization of CEVE and styrene derivatives $^{13}$ is influenced very much by the kind of catalyst in toluene or methylene chloride but little in nitrobenzene.

In this study, it has been made clear that the kind of catalyst brings about a great change not only in the polymerization rate but also in the molecular weight of polymer and that the added salts behave in a very similar manner.
From these results, it is concluded that a counter-ion other than that from the catalyst used also exists when a salt is added. Hence, the propagating species in the presence of a salt can be illustrated as in Scheme $\mathbf{I}$.

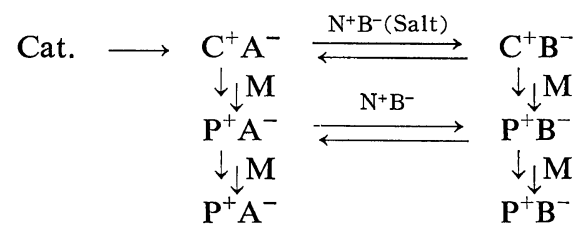

Scheme I

It is not clear whether the exchange of a counter-ion occurs both at the stage before propagation and during propagation, or only at either stage. If a counter-ion does not exchange during propagation at all, a mixture of polymers with different structures and properties will be produced because of different counterions. Further investigations are in progress on this problem.

\section{REFERENCES}

1. I. M. Panayatov, I. K. Dimitrov, and I. E. Bakerdjiev, J. Polym. Sci., Part A-1, 7, 2421 (1969).

2. R.S. Velichkova and I. M. Panayatov, Makromol. Chem., 138, 171 (1970).

3. e.g., M. Shinohara, J. Smid, and M. Szwarc, J. Amer. Chem. Soc., 90, 2175 (1968).

4. M. Tomoi and H. Kakiuchi, Kogyo Kagaku Zasshi (J. Chem. Soc. Japan, Ind. Chem. Sect.), 73, 2367 (1970).

5. L. E. Darcy, W. P. Millrine, and D. C. Pepper, Chem. Commn., 1441 (1968).

6. B. McCarthy, W. P. Millrine, and D. C. Pepper, ibid., 1442 (1968).

7. D. C. Pepper, University of Dublin, private communication, 1969.

8. S. Tazuke, Chem. Commn., 1277 (1970).

9. T. Masuda and T. Higashimura, J. Polym. Sci., Part A-1, 9, 1563 (1971).

10. H. Hostalk, R. V. Figini, and G. V. Schulz, Makromol. Chem., 71, 198 (1964).

11. H. L. Hsieh, J. Polym. Sci., Part A-1, 8, 533 (1970), and the preceding papers.

12. T. Higashimura, T. Masuda, and S. Okamura, J. Polym. Sci., Part A-1, 7, 667 (1969).

13. T. Masuda and T. Higashimura, J. Macromol. Sci.-Chem., A5, 549 (1971). 